\title{
Chronic unremitting headache associated with Lyme disease-like illness
}

\author{
Dor de cabeça incessante crônica associada com a doença de Lyme símile \\ Pedro André Kowacs ${ }^{1,2,3}$, Rodrigo Tomazini Martins', Elcio Juliato Piovesan³, Maria Cristina Araujo Pinto 4 , \\ Natalino Hagime Yoshinari ${ }^{5}$
}

\begin{abstract}
The Brazilian Lyme-disease-like illness (BLDLI) or Baggio-Yoshinari syndrome is a unique zoonosis found in Brazil. It reproduces all the clinical symptoms of Lyme disease except for the high frequencies of relapse and the presence of autoimmune manifestations. Two cases of borreliosis manifesting with unremitting headache, which is a symptom associated with late-stage BLDLI, were presented. Clinical, therapeutic, and prognostic aspects of the BLDLI and its associated headaches were showed and discussed in this article. BLDLI diagnosis requires additional attention by physicians, since the disease has a tendency to progress to the late, recurrent stage or the chronic form, and the associated headache can be confused with chronic primary headache or with analgesic-overuse one. Special attention should be paid to patients with headaches who have traveled to endemic areas.
\end{abstract}

Key words: borrelia burgdorferi, erythema chronicum migrans, headache disorders, Lyme disease, zoonoses.

\section{RESUMO}

A doença de Lyme símile brasileira (BLDLI) ou síndrome de Baggio-Yoshinari é uma zoonose diferenciada encontrada no Brasil. Ela reproduz todos os sintomas clínicos da doença de Lyme, exceto as altas frequências de recidivas e a presença de manifestações autoimunes. Dois casos de borreliose, manifestando-se com cefaleia incessante, que é um sintoma associado à fase tardia da BLDLI, foram apresentados. Os aspectos clínicos, terapêuticos e prognósticos da BLDLI, bem como as cefaleias associadas com a doença de Lyme, foram mostrados e discutidos. O diagnóstico da BLDLI requer maior atenção dos médicos, já que a doença tende a progredir em seu estágio tardio, na forma recorrente ou crônica, e a cefaleia pode ser confundida com cronificação primária ou por abuso excessivo de analgésicos. Atenção especial deve ser dada aos pacientes que viajaram para áreas endêmicas.

Palavras-Chave: borrelia burgdorferi, eritema migrans crônico, transtornos da cefaleia, doença de Lyme, zoonoses.

Lyme disease (LD) is a multifaceted infectious disease ${ }^{1}$ caused by Borrelia burgdorferi sensu lato spirochetes, which are transmitted to humans by tick bites in at-risk areas in the Northern hemisphere ${ }^{2,3}$. Since this microorganism is difficult to culture, the disease is usually diagnosed by serological tests ${ }^{3}$. The most common neurological presentations of $\mathrm{LD}$ are meningitis, cranial neuritis, and radiculoneuritis ${ }^{4}$.

Brazilian Lyme-disease-like illness (BLDLI) or BaggioYoshinari syndrome (BYS) is a unique zoonosis found in Brazil. It reproduces all clinical symptoms of LD except for the high frequencies of relapse and the presence of autoimmune manifestations ${ }^{5-7}$. The vector of BLDLI belongs to genera
Amblyomma and Rhipicephalus rather than to the Ixodes ricinus complex, which is responsible for transmission in the Northern hemisphere ${ }^{6,8,9}$.

To date, the etiologic agent has not been isolated or cultured in Brazil. However, electron microscopy analysis of patients' blood samples showed microorganisms resembling spirochetes with atypical morphologies ${ }^{5}$. Recently, a polymerase chain reaction (PCR) analysis carried out with primers derived from the flgE gene has proven that Brazilian zoonosis is caused by microorganisms from Borrelia .

Since the etiological agents of BLDLI and LD are different, researchers from Laboratório de Investigações Médicas-17

\footnotetext{
${ }^{1}$ Neurology Department, Instituto de Neurologia de Curitiba, Curitiba PR, Brazil;

${ }^{2}$ Neurology Department, Curitiba PR, Brazil;

${ }^{3}$ Departamento de Clínica Médica do Hospital das Clínicas, Universidade Federal do Paraná (UFPR), Curitiba PR, Brazil;

${ }^{4}$ Dermatologist, Curitiba PR, Brazil;

${ }^{5}$ Laboratório de Investigação em Reumatologia do Hospital das Clínicas, Faculdade de Medicina, Universidade de São Paulo (USP), São Paulo SP, Brazil.

Correspondence: Pedro André Kowacs; Rua Jeremias Maciel Perretto 300;81510-350 Curitiba PR - Brasil; E-mail: pkowacs@gmail.com

Conflict of interest: There is no conflict of interest to declare.

Received 14 August 2012; Received in final form 12 March 2013; Accepted 19 March 2013.
} 
(LIM-17), Hospital das Clínicas da Faculdade de Medicina da Universidade de São Paulo - HCFMUSP (the Brazilian Reference Center for BLDLI research) developed diagnostic criteria specifically to confirm suspected cases of Brazilian borreliosis (Table 1$)^{5}$. Serological tests - ELISA and Western blotting (WB) - were carried out with the North American G39/40 strain of Borrelia burgdorferi, isolated primarily from Ixodes scapularis.

Two cases of neuroborreliosis associated with unremitting headache, which is a symptom associated with late-stage BLDLI, are presented herein. This symptom can be unnoticed or misdiagnosed by Brazilian physicians due to its difficult diagnosis and late appearance in the course of the disease.

\section{CASE REPORTS}

\section{Case 1}

A 44-year-old female dentist whose migraine without aura was controlled in the previous year with atenolol $25 \mathrm{mg}$ one day (QD), presented in November 2009 due to worsening of her headaches. Previous medical consultations had identified benign postural vertigo, symptomatic cervical disk herniation, allergic rhinitis, hiatal hernia, saphenectomy, and hysterectomy. The patient reported that her first headache attacks due to BLDLI were quite similar to her previous migraine ones and responded well to the use of over-the-counter (OTC) drugs (simple analgesic drugs and/or nonsteroidal anti-inflammatory drugs - NSAIDs).

After six months, when the diagnosis of Lyme-like disease was concluded, her headaches were occurring daily without any respite and were no longer responsive to simple analgesic drugs, NSAIDs, or anti-migraine drugs such as dihydroergotamine (DHE) or triptans. The patient also stated that the headaches were accompanied by anorexia, nausea, disequilibrium, and depressive mood. In the patient's own words: "it was just like having migraine and labyrinthitis together, but on a larger scale." The participant also reported that at that time, she was experiencing a decrease in the quality of her sleep and waking up tired. Atenolol was withdrawn, and methysergide and trazodone were started without success. Meanwhile, she consulted a dermatologist because of a skin lesion in her left groin, which was diagnosed as erythema migrans (EM). A review of her history revealed that she had been having some dizziness and minor joint and ankle pains. She denied history of tick bites but said that recently, during her vacations, she had worked in a mission in Northern Brazil, a known risk area for BLDLI.

The brain magnetic resonance imaging (MRI) revealed a small hyperintense lesion in the head of the left caudate nucleus (Figure) and a bilaterally delayed P100 latency in her visual evoked responses. Her cerebrospinal fluid (CSF) examination was normal. Serology for B. burgdorferi was performed at LIM-17 HCFMUSP and was positive (WB: IgG, two bands; IgM, one band). The patient received intravenous ceftriaxone $2 \mathrm{~g}$ one day (QD) for 30 days and then doxycycline $100 \mathrm{mg}$ twice a day (BID) for three months. Her frequent headaches and dizziness had already abated when she was receiving intravenous therapy, but the joint pains remitted only after sulphasalazine $1 \mathrm{~g}$ BID and hydroxychloroquine $400 \mathrm{mg}$ QD had been added.

In February 2011, the woman had a recurrence of EM (a secondary annular skin lesion) on her left ankle, and doxycycline $100 \mathrm{mg}$ BID for three months was restarted. A control MRI revealed that the left caudate lesion had been solved. In July 2011 topiramate 25 mg BID was started for

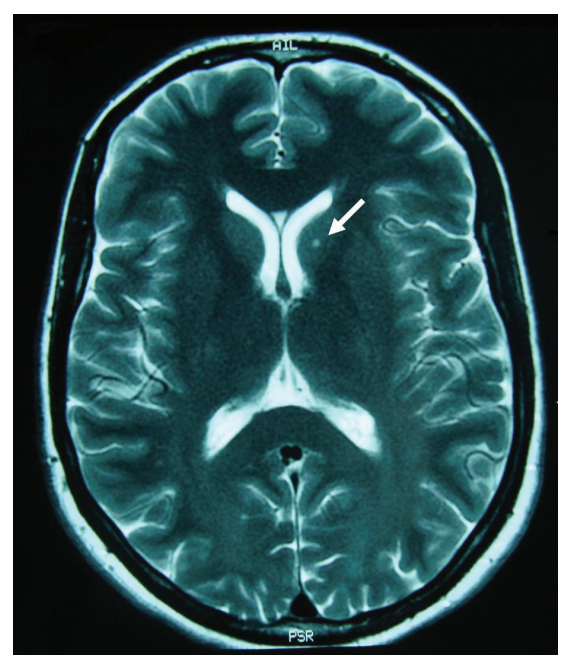

Figure. T2-weighted axial brain magnetic resonance images. Note the round area of high signal intensity in the head of the caudate nucleus (arrow). This appeared at the onset of the Brazilian Lyme Disease-like illness and disappeared after antibiotic treatment.

Table 1. Diagnostic criteria for the Brazilian Lyme disease-like illness adopted by LIM-175.

\footnotetext{
Major criteria

Epidemiology (tick bite or contact with wild or domestic animals in risk areas)

Erythema migrans or systemic manifestation (arthritis, neurological abnormalities, cardiac involvement)

Positive serology for Borrelia burgdorferi

Minor criteria

Relapsing symptoms

Chronic fatigue or cognitive disturbances

Identification of spirochete-like structures by dark-field microscopy or Giemsa staining
}

Cases are defined as positive if three or two major and two minor criteria are positive. 
her continuing migraines, and trazodone was reintroduced for her disturbed sleep. In November 2011, she started a new course of ceftriaxone because of bilateral retinal lesion.

\section{Case 2}

A 40-year-old female presented in April 2011 with intractable headaches. She had had sporadic nondisabling headaches since her twenties, but at the age of 37 (in 2008) her attacks increased in frequency and intensity and became disabling. The headaches were bilateral, pressure-like or throbbing with a temporo-parieto-occipital distribution, being stronger in the occipital region. The pain would reach a tenpoint intensity on a ten-point verbal pain scale with dizziness. Attacks were accompanied by nausea and intense osmophobia, but not by photophobia or phonophobia. They did not happen at any specific time, and occurred up to twice a week. They lasted from 24 to 72 hours, sometimes starting early in the morning and getting worse in the evening.

Her medical history revealed a sequela of toxoplasmosis in her left eye, intermittent vertigo, allergic rhinitis, gastroesophageal reflux, cervical disk herniation, femoral dysplasia, and three pregnancies (two until term and one spontaneous abortion). She had also had an EM lesion over her left shoulder in 2005 and bilateral knee pains starting thereafter. Her neurological examination was unremarkable. The brain MRI was normal, as was the CSF fluid examination. Serology for antibodies to B. burgdorferi was performed at LIM-17 HCFMUSP and proved to be positive WB (IgG, one band; IgM, two bands), satisfying the Brazilian Reference Center's standard criteria for diagnosis of Brazilian borreliosis. Because of her past history of EM and arthritis, BLDLI was diagnosed and treated with intravenous ceftriaxone $2 \mathrm{~g}$ QD for 30 days followed by doxycycline $100 \mathrm{mg}$ BID for three months. Her frequent headaches, dizziness, and knee pains abated at the beginning of intravenous ceftriaxone therapy and had not recurred at the time of writing. However, she was placed on atenolol and flunarizine for the infrequent migraine headaches. She continued to have mild sporadic bitemporal headaches, which got worse in the evening. Also, she did not have any associated symptoms, and these were enhanced by heat and occurred twice a month.

\section{DISCUSSION}

BLDLI, also known as BYS, is a new zoonosis described in Brazil. It differs from LD in that to date its etiological agent has not been isolated, its vector does not belong to the Ixodes ricinus complex, and its clinical symptoms are often recurrent ${ }^{6,10,11}$.

Researchers from LIM-17 HCFMUSP believe that geographic conditions and ecological biodiversity in Brazil favored the evolution of spirochetes with atypical morphologies adapted for survival in Brazilian vertebrate and invertebrate hosts 6 . Borrelias with atypical morphologies tend to survive inside host cells and become resistant to antibiotics and antibodies, explaining the occurrence of relapsing symptoms and low immune reactivity to $B$. burgdorferi sensu lato antigen ${ }^{5,9-11}$. These BLDLI peculiarities explain why Brazilian patients usually do not meet the Centers for Disease Control and Prevention (CDC) criteria for serologic diagnosis of $\mathrm{LD}$.

In light of this, LIM-17 HCFMUSP established the following diagnostic criteria for recognizing most suspected cases of BLDLI in Brazil (Table1) ${ }^{5}$ : epidemiology, clinical manifestations and serology (major criteria); and relapsing symptoms, chronic fatigue and/or cognitive disturbances and identification of spirochete-like microorganisms by dark field microscopy (minor criteria). A positive diagnosis is made if the results for three major criteria or two major and two minor criteria are positive.

Patients with BLDLI present with EM in nearly $50 \%$ of the cases. In the secondary stage of the disease, arthritis and neuropathy are observed in $35 \%$, and cardiac manifestation in $5 \%^{6}$. Relapsing episodes are found in almost $75 \%$ of the situations when patients are diagnosed in the late stage of the disease (more than three months after disease onset) even after antibiotic treatment ${ }^{6,10,11}$.

Both patients reported here came to the service with previous EM, arthritis, and positive serology for B. burgdorferi. Interestingly, patient 1 had recurrent skin lesion (secondary annular erythema) and bilateral retinal lesion even after antibiotic treatment, confirming that BLDLI has late relapsing symptoms. Shinjo et al. ${ }^{11}$ studied 30 patients with neuropsychiatric symptoms related to BLDLI and found meningitis in $50 \%$ of their series, peripheral motor neuropathy in $40 \%$, peripheral sensitive neuropathy in $33.3 \%$, encephalitis/myelitis in $33 \%$, facial palsy in $26.7 \%$, ocular symptoms in $36.7 \%$, dysacusis in $10 \%$, dysarthria in $6.7 \%$, dysphagia in $6.7 \%$, and psychiatric symptoms in $20 \%$. It is noteworthy that EM was reported by $43.3 \%$ of neurological patients and arthritis by $50 \%$. Extended follow-up of some of them showed that $73.3 \%$ had recurrent symptoms. In addition, the frequency of skin lesions diminished as the disease progressed, making it very difficult to identify BLDLI in the late relapsing stage.

Treatment of BLDLI is also different from that recommended for LD. In the acute stage of the disease, doxycycline $100 \mathrm{mg}$ twice a day for at least three weeks is recommended. If the disease is diagnosed more than three months after onset, continued treatment with the same substance for three months is recommended. If neurological symptoms are present, the use of ceftriaxone $2 \mathrm{~g} /$ day for one month with an additional three-month course of doxycycline is indicated.

Several types of headaches have been reported to be associated with $\mathrm{LD}^{4,12,13,15-18}$ (Table 2). In a large sample of confirmed LD patients, headache, orofacial, and dental pains were reported to be common complaints ${ }^{12}$. Migraine has been described in approximately half of inpatients with 
confirmed LD and is more common in those with central nervous system involvement ${ }^{13}$. In a study by Avery et al. ${ }^{14}$, approximately one-third of LD headache patients had meningitis or other signs of central nervous system involvement.

Headache in LD has also been described to occur in association with cranial nerve involvement ${ }^{14}$, ocular disease ${ }^{15}$, and temporal arteritis ${ }^{16}$. However, there are few reports of $\mathrm{LD}$ where chronic unremitting headache is the only primary symptom $^{4,16-18}$.

Diagnosis of atypical headaches can pose a problem, especially in patients who previously presented with migraine headaches, since in these patients non-migrainous ones may be a part of the spectrum of migraine ${ }^{19}$. Indeed, diagnosis of chronic, unremitting headache in association with LD or BLDLI is difficult and can be confused with chronification of primary or with analgesic-overuse headaches ${ }^{13,17,18}$. Nevertheless, making the correct diagnosis is important because when this symptom is associated with borreliosis, it has a tendency to remit with antibiotic therapy, as in the cases described.

Thus, ecotravelers presenting with new and/or chronic headaches must be carefully screened for visits to geographic risk areas, tick bite episodes, and contact with animals. Diagnosis of BLDLI requires additional attention by physicians, since the disease has a tendency to progress to the late, recurrent stage or to the chronic form. Unfortunately, patients' remote epidemiological and clinical history, which is important for recognizing the disease, may be neither
Table 2. Types of headaches described to date in patients with Lyme Disease.

Unspecified chronic or unremitting headaches ${ }^{4,16-18}$

Migraine-like headaches ${ }^{13}$

Tension-type headaches ${ }^{17}$

Headaches associated with intracranial hypertension ${ }^{4,17}$

Headaches associated with Lyme Disease meningitis $4,13,17$

Headaches associated with cranial nerve involvement ${ }^{13}$

Headaches associated with ocular disease ${ }^{15}$

Headaches resembling temporal arteritis ${ }^{16}$

Facial, dental, and/or orofacial pain ${ }^{12}$

investigated by physicians nor spontaneously recalled by patients themselves. Notably, acute disease stage could happen in weeks, months, or years from the current symptoms. In this respect, special attention should be paid to patients who have traveled to endemic areas.

BLDLI is a very frequent, neglected, and unrecognized infectious and reactive syndrome. The dissemination of knowledge about BLDLI among physicians is of great importance in view of the elusive nature of the disease.

\section{ACKNOWLEDGEMENTS}

The authors would like to thank Marisa Avellar de Morais and Cibele Motta Gonçalves for their invaluable help in preparing the manuscript.

\section{References}

1. Burgdorfer W, Barbour AG, Hayes SF. Lyme disease: a tick borne spirochetosis. Science 1982;216:1317-1319.

2. Steere AC, Malawista SE, Snydman DR, et al. Lyme arthritis: an epidemic of oligoarticular arthritis in children and adults in three Connecticut communities. Arthritis Rheum 1977;20:7-17.

3. Steere AC. Lyme disease. N Engl J Med 2001;345:115-125.

4. Pachner AR, Steere AC. The triad of neurologic manifestations of Lyme disease: meningitis, cranial neuritis, and radiculoneuritis. Neurology 1985;35:47-53.

5. Mantovani E, Costa IP, Gauditano G, Bonoldi VLN, Higuchi ML, Yoshinari NH. Description of Lyme disease-like syndrome in Brazil. Is it a new tick borne disease or Lyme disease variation? Braz J Med Biol Res 2007;40:443-456.

6. Yoshinari NH, Mantovani E, Bonoldi VL, Marangoni RG, Gauditano G. [Brazilian Lyme-like disease or Baggio-Yoshinari syndrome: exotic and emerging Brazilian tick-borne zoonosis]. Rev Assoc Med Bras 2010;56:363-369.

7. Costa IP, Bonoldi VLN, Yoshinari NH. Search for Borrelia sp in ticks from potential reservoir in an urban forest in the State of Mato Grosso do Sul, Brazil: a short report. Mem Inst Oswaldo Cruz 2002;97:631-635.

8. Abel IS, Marzagão G, Yoshinari NH, Schumaker TT. Borrelia-like spirochetes recovered from ticks and small mammals collected in the Atlantic Forest Reserve, Cotia county, State of São Paulo, Brazil. Mem Inst Oswaldo Cruz 2000;95:621-624.

9. Mantovani E, Marangoni RG, Gauditano G, Bonoldi VL, Yoshinari NH. Amplification of the flgE gene provides evidence for the existence of a Brazilian borreliosis. Rev Inst Med Trop Sao Paulo 2012;54:153-157.
10. Gouveia EA, Alves MF, Mantovani E, Oyafuso LK, Bonoldi VL, Yoshinari $\mathrm{NH}$. Profile of patients with Baggio-Yoshinari Syndrome admitted at "Instituto de Infectologia Emilio Ribas". Rev Inst Med Trop São Paulo 2010;52:297-303.

11. Shinjo SK, Gauditano G, Marchiori PE, et al. Manifestação neurológica na síndrome de Baggio-Yoshinari (sindrome brasileira semelhante à doença de Lyme). Rev Bras Reumatol 2009;49:492-505.

12. Heir GM, Fein LA. Lyme disease awareness for the New Jersey dentist. A survey of orofacial and headache complaints associated with Lyme disease. J N J Dent Assoc 1998;69:62-63.

13. Scelsa SN, Lipton RB, Sander H, Herskovitz S. Headache characteristics in hospitalized patients with Lyme disease. Headache 1995;35:125-130.

14. Avery RA, Frank G, Glutting JJ, Eppes SC. Prediction of Lyme meningitis in children from a Lyme disease-endemic region: a logistic-regression model using history, physical, and laboratory findings. Pediatrics 2006;117:1-7.

15. Wiegand W. Eye manifestations in borreliosis--bilateral panuveitis with exudative retinal detachment. Fortschr Ophthalmol 1989;86:659-662.

16. Pizzarello LD, MacDonald AB, Semlear R, DiLeo F, Berger B. Temporal arteritis associated with Borrelia infection. A case report. J Clin Neuroophthalmol 1989;9:3-6.

17. Brinck T, Hansen K, Olesen J. Headache resembling tension-type headache as the single manifestation of Lyme neuroborreliosis. Cephalalgia 1993;13:207-9.

18. Moses JM, Riseberg RS, Mansbach JM. Lyme disease presenting with persistent headache. Pediatrics 2003;112:e477-e479.

19. Lipton RB, Cady RK, Stewart WF, Wilks K, Hall C. Diagnostic lessons from the spectrum study. Neurology 2002;58(Suppl 6):S27-S31. 